\title{
Spinal cord compression secondary to metastasis of malignant chondroid syringoma: case report
}

\author{
Ricardo H. Menéndez, MD,1 Santiago G. Erice, MD, ${ }^{1}$ Carlos A. Bas, MD, ${ }^{2}$ Gabriel Casas, MD, ${ }^{3}$ \\ and Horacio S. Dillon, MD'
}

Departments of ${ }^{1}$ Neurosciences, ${ }^{2}$ Clinical Oncology, and ${ }^{3}$ Pathology, Hospital Aleman, Buenos Aires, Argentina

\begin{abstract}
The authors describe a case of spinal cord compression due to an epidural metastasis of malignant chondroid syringoma. Chondroid syringoma is a rare mixed tumor of the skin composed of both epithelial and mesenchymal elements. Although most are benign, malignant forms have been reported. Malignant chondroid syringoma may progress very slowly and the metastatic spread occurs late, appearing years after the original diagnosis. There is only one other report of spinal cord compression secondary to metastasis of malignant chondroid syringoma, which was finally diagnosed by microscopic examination of an autopsy specimen.

This 63-year-old woman presented with a 4-week history of progressive paraparesis. Admission MRI of the thoracic spine showed an extradural mass arising from the posterior elements and left pedicle of T-9, which caused posterior compression of the spinal cord. Surgical decompression resulted in resolution of the neurological impairments. The histological results were consistent with metastasis of malignant chondroid syringoma. The patient underwent adjuvant radiotherapy and a favorable outcome was noted at the 2-year follow-up visit. This represents the first reported case of spinal cord compression from a metastasis of a malignant chondroid syringoma histologically confirmed in vivo. The authors' experience in this case suggests that resection followed by radiotherapy might be an acceptable means for achieving short-term, progression-free survival.
\end{abstract}

http://thejns.org/doi/abs/10.3171/2014.9.SPINE14360

KEY WORDS malignant chondroid syringoma; metastases; spinal cord compression; oncology

$\mathrm{C}$ HONDROID syringoma is a rare mixed tumor of the skin that was firstly described by Hirsch and Helwig. ${ }^{5}$ The term was proposed because of the presence of sweat gland elements included in a cartilaginous stroma. The incidence of chondroid syringoma is very low, reported as $0.01 \%$ of all primary skin tumors. ${ }^{20}$ Lesions are typically benign, are located on the head and neck, sparing the extremities, and affect middle-aged men. ${ }^{15}$ Although most reported cases of chondroid syringoma have been benign, several cases of malignancy have been reported. ${ }^{1-3,7-9,11,14,17,18,20-22}$ Malignant chondroid syringoma is the least common variety of sweat gland carcinoma. ${ }^{10,22}$ In contrast to its benign counterpart, the malignant form occurs predominantly in women of any age and is observed more commonly in the trunk and extremities. ${ }^{3,15}$ Although malignant chondroid syringoma can progress very slowly, recurrence and metastasis are frequent, usually involving the lymph nodes, lungs, or both. ${ }^{1,8,16,21}$ Bone and widespread metastases are less common. ${ }^{7,17,22}$ We identified only one other report describing spinal cord compression secondary to the metastasis of a malignant chondroid syringoma, but the definitive diagnosis was made by autopsy. ${ }^{7}$ To our knowledge, ours is the first case in the MRI era that was diagnosed, treated, and observed in follow-up studies.

We discuss the clinical presentation, imaging characteristics, and treatment of this lesion and also review the pertinent literature.

\section{Case Report}

History

This 63-year-old woman presented in June 2011 with a 4-week history of progressive weakness and numbness in the lower limbs. She had been experiencing increasing difficulty with walking, and her neurological deficit had 
worsened over the preceding 15 days. At admission, she required assistance with a rolling walker. In 1990, she had undergone resection of a subcutaneous nodule in the epigastrium, and the lesion was diagnosed as a malignant chondroid syringoma. Seven years after the resection, the tumor recurred in the same site and was again excised. In 2004 the tumor again recurred locally and a liver metastasis was also found. She underwent left hepatic lobectomy and partial resection of the thoracoabdominal wall with thoracoplasty. In 2005 a mass in the right kidney was diagnosed, and a partial nephrectomy was performed. Histopathological examination was, again, consistent with malignant chondroid syringoma.

\section{Examination}

Neurological examination disclosed a spastic paraparesis. The patient had Grade 2/5 lower-extremity strength on the left side and Grade 3/5 lower-extremity strength on the right. Muscle tone was increased bilaterally, predominantly in the left. Patellar and Achilles reflexes were Grade $3+/ 5$ in both extremities and she had bilateral Babinski signs. She also exhibited hypesthesia with a decrease in temperature and light touch sensations below the T-10 dermatome. Vibration and joint position sense were diminished bilaterally. Bowel and bladder functions were normal. Magnetic resonance imaging of the thoracic spine revealed an extradural mass arising from the posterior arch elements and the left pedicle of T-9, which caused compression of the spinal cord at the T8-9 level. The lesion was hypointense on T1-weighted imaging and hyperintense on T2-weighted imaging (Fig. 1).

\section{Operation and Postoperative Course}

We performed a T8-9 laminectomy. Intraoperatively we observed that the spinal cord was displaced anterolaterally by a soft, reddish, well-vascularized epidural lesion. Dissection revealed a plane between the tumor and the

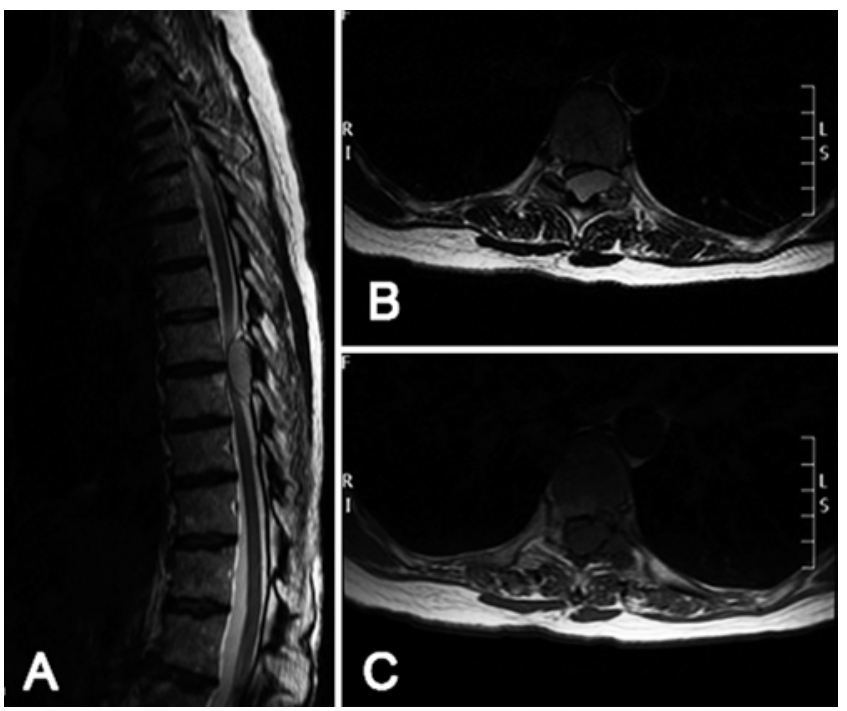

FIG. 1. Admission sagittal T2-weighted (A), axial T2-weighted (B), and axial T1-weighted $(C)$ MR images of the thoracic spine revealing an extradural mass projecting into the spinal canal and causing anterior displacement of the spinal cord to the right. dura. The mass was removed and the spinal cord thereby decompressed. The tumor had infiltrated the left pedicle of T-9 and could not be completely resected. Instrumented fusion was not performed. The patient made an uneventful postoperative recovery, experienced gradual improvement in her paraparesis, and was discharged on postoperative Day 14 .

\section{Pathological Findings}

There was a lobulated proliferation composed of a predominant epithelial component and a mesenchyme-like component, the latter consisting of myxomatous areas (Fig. 2 upper). The epithelial component had a nested pattern, with cords and nests of cuboidal to polygonal cells with some glandular structures. There was mild pleomorphism and scattered mitosis (Fig. 2 lower). These histological findings were consistent with a metastasis of malignant chondroid syringoma.

\section{Adjuvant Therapy}

Surgery was followed by adjuvant radiation treatment

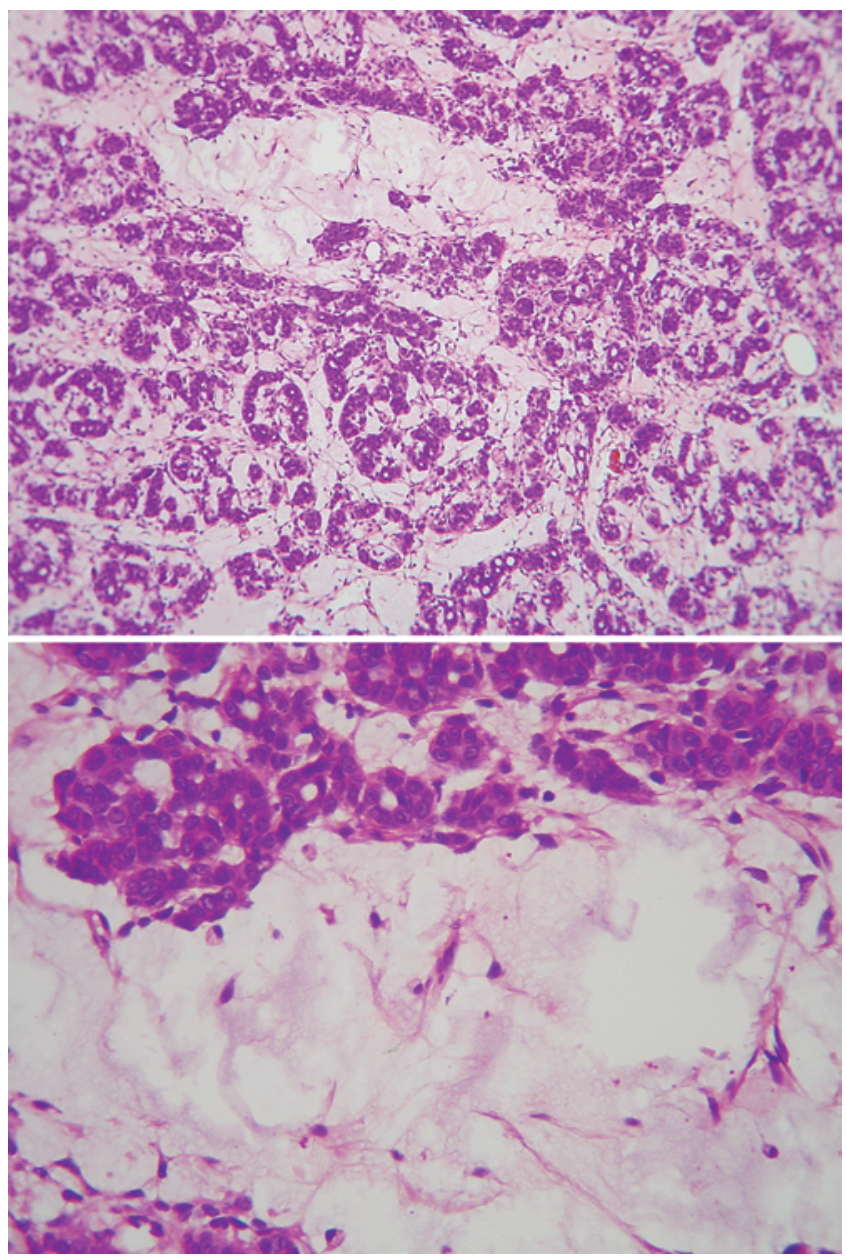

FIG. 2. Photomicrographs showing the tumor's histopathological features. Upper: A lobulated tumor composed of epithelial cuboidal to polygonal cells with some glandular structures, surrounded by a myxomatous stroma. Lower: A myxomatous stroma is evident. The epithelial component shows variable pleomorphism. $\mathrm{H} \& \mathrm{E}$, original magnification $\times 10$ (upper) and $\times 40$ (lower). Figure is available in color online only. 
with conventional radiotherapy. A long-course schedule of $40 \mathrm{~Gy}$ in 20 fractions was applied.

\section{Follow-Up}

At the 1-year follow-up examination, the patient's motor strength had improved to Grade 5/5 in both legs, and this persisted after 2 years. Also, she experienced resolution of lower-extremity sensory disturbances. MRI of the thoracic spine performed at 3,12, and 24 months postoperatively revealed residual disease in the left pedicle of T-9 without progression and showed adequate neural decompression (Fig. 3).

\section{Discussion}

Chondroid syringoma is an uncommon mixed cutaneous neoplasm arising from the eccrine sweat glands. Histologically the tumor is composed of an epithelial and a mesenchymal component. ${ }^{10}$ There are benign and malignant variants. ${ }^{13,15}$ The malignant type, reported in the present case, constitutes an extremely rare tumor with very few cases reported in the literature. It occurs mostly in females and is commonly seen in the trunk and extremities. ${ }^{14,15}$ Diagnosis is based on pathological features, but it is complicated by the low frequency of this tumor. The histopathological features of the malignant variant may be very similar to the benign type, and the differentiation between them becomes difficult. $4,8,19$

The aggressiveness of malignant chondroid syringoma is variable, with approximately $50 \%$ of cases having local recurrence. ${ }^{21}$ Metastasizing malignant chondroid syringoma was first reported by Rosborough in $1963 .{ }^{12}$ Distant metastases occur after multiple local recurrences of the primary tumor and have been observed in approximately $40 \%$ of cases, usually involving the lymph nodes, ${ }^{21}$ lungs, ${ }^{8,16}$ or both. Bone and widespread metastases are less common. $7,17,22$

Involvement of the spinal column is extremely rare. Ishimura et al. reported a case of a 73-year-old man who died of complications associated with compression of the upper thoracic spinal cord, 13 years after the initial diagnosis of malignant chondroid syringoma in his back. In that case, myelography showed an extradural mass and autopsy revealed a paravertebral mass involving the T-3 and T-4 vertebrae with histopathological findings similar to the original tumor. This is the only case of spinal cord compression due to metastatic malignant chondroid syringoma described in the literature. However, this patient did not undergo surgery or radiotherapy. Only supportive therapy was continued. ${ }^{7}$

In our case, the primary tumor recurred after resection and metastasized during a long clinical course. Liver and kidney metastases were discovered 14 and 15 years after removal of the primary tumor, respectively. The spinal metastasis appeared 21 years after excision of the skin tumor. MRI accurately demonstrated the extent of the anatomical compromise, bone invasion, and cord compression.

Treatment of metastatic lesions depends on the location, but total surgical excision is recommended when possible. ${ }^{18}$ Complementing surgical treatment with radiotherapy for this entity is still controversial., ${ }^{2,6,16}$ Although
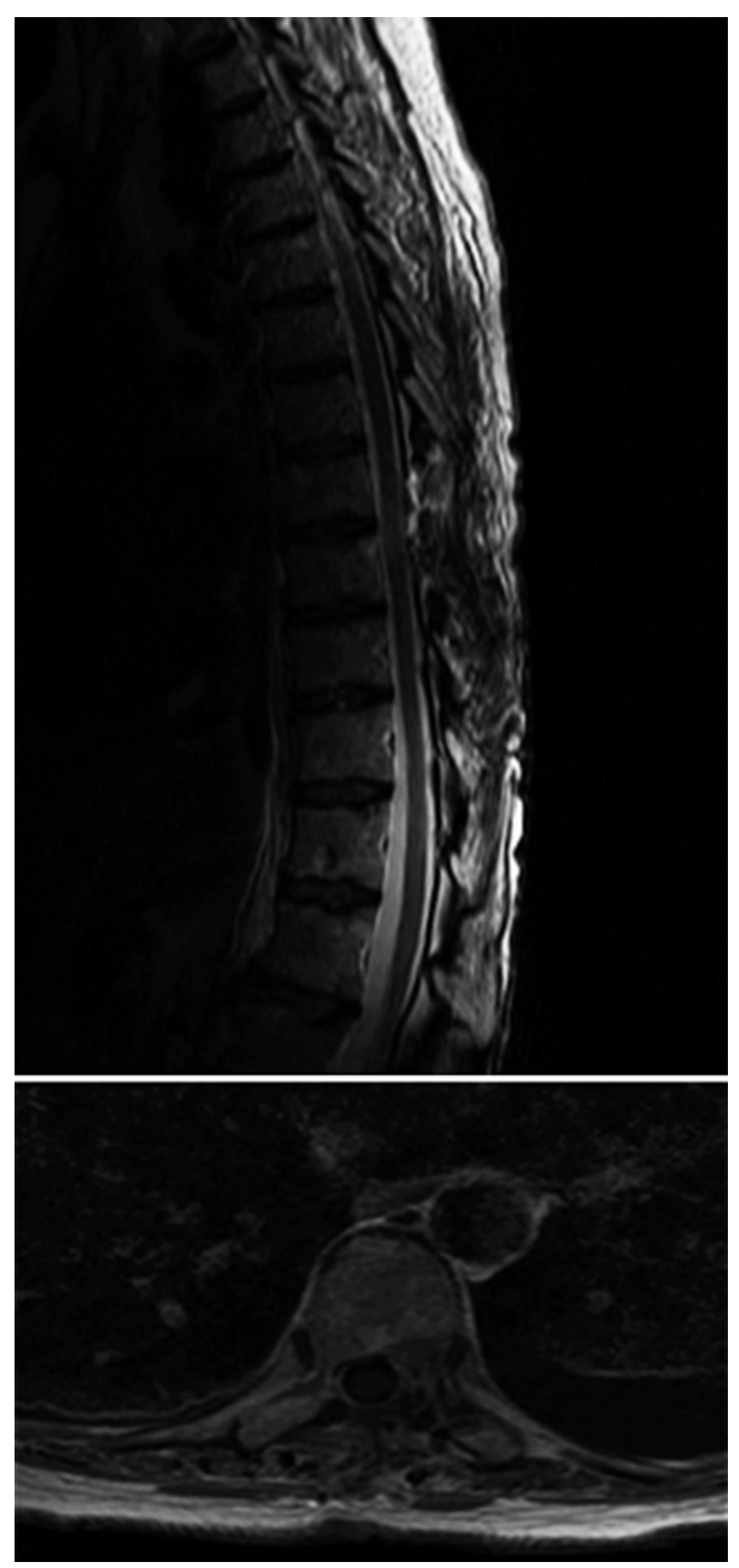

FIG. 3. Two-year postoperative sagittal T2-weighted (upper) and axial T1-weighted (lower) MR images showing minimal residual disease in the left pedicle of T-9. No progression was observed.

local radiotherapy is often unsuccessful, skeletal metastases have shown a response to radiotherapy. If we take into account all malignancies, Level I evidence suggests that surgery followed by radiotherapy remains the treatment of choice for selected patients presenting with spinal cord compression caused by a metastatic lesion. The choices of radiation dose and fractionation regimen in the postoperative setting depend on multiple factors including life expectancy and tumor type. Long-course radiotherapy with 
higher doses may be associated with better local control and fewer in-field recurrences, which would be an advantage in a patient expected to live longer, like the woman in the present case. Combined chemotherapy with surgery and radiotherapy in patients with metastasis has not been reported as beneficial. ${ }^{14}$

We chose a bimodal approach that included surgery and subsequent radiotherapy. Surgical treatment was performed to decompress the spinal cord and preserve neurological function. The patient underwent postoperative irradiation of the spinal resection bed with a long-course schedule of 40 Gy in 20 fractions and her condition remains stable after 2 years of follow-up. Radiotherapy likely played a role in delaying the spinal progression in this case. Long-term follow-up will indicate if this treatment protocol was appropriate.

\section{Conclusions}

To the best of our knowledge, this is the first report of spinal cord compression caused by a metastasis of a malignant chondroid syringoma, diagnosed, treated, and with follow-up studies.

Given the rarity of this tumor and the lack of published experience in the therapeutic management of spinal secondary lesions, we can suggest some recommendations based on this case. Resection followed by radiotherapy may be an acceptable approach to achieve short-term, progression-free survival. Radiotherapy should be tried in future cases of incomplete excision or as a palliative therapy. Because disease recurrence including metastasis will occur in a high percentage of cases, long-term followup is required.

\section{Acknowledgment}

We are indebted to Dr. Elisa Estenssoro for English editing of the manuscript.

\section{References}

1. Agrawal V, Gupta RL, Kumar S, Mishra K, Agarwal S: Malignant chondroid syringoma. J Dermatol 25:547-549, 1998

2. Araújo JL, de Aguiar GB, do Prado Aguiar U, Mayrink D, Saade N, Veiga JC: Malignant chondroid syringoma with central nervous system involvement. J Craniofac Surg 23:514-515, 2012

3. Barnett MD, Wallack MK, Zuretti A, Mesia L, Emery RS, Berson AM: Recurrent malignant chondroid syringoma of the foot: a case report and review of the literature. Am J Clin Oncol 23:227-232, 2000

4. Bates AW, Baithun SI: Atypical mixed tumor of the skin: histologic, immunohistochemical, and ultrastructural features in three cases and a review of the criteria for malignancy. Am J Dermatopathol 20:35-40, 1998

5. Hirsch P, Helwig EB: Chondroid syringoma. Mixed tumor of skin, salivary gland type. Arch Dermatol 84:835-847, 1961

6. Hong JJ, Elmore JF, Drachenberg CI, Jacobs MC, Salazar OM: Role of radiation therapy in the management of malignant chondroid syringoma. Dermatol Surg 21:781-785, 1995

7. Ishimura E, Iwamoto H, Kobashi Y, Yamabe H, Ichijima K:
Malignant chondroid syringoma. Report of a case with widespread metastasis and review of pertinent literature. Cancer 52:1966-1973, 1983

8. Kiely JL, Dunne B, McCabe M, McNicholas WT: Malignant chondroid syringoma presenting as multiple pulmonary nodules. Thorax 52:395-396, 1997

9. Medina Henriquez JA, Navarro Garcia R, Nagel D, Foucher G: Malignant chondroid syringoma of the hand: a case report. Scand J Plast Reconstr Surg Hand Surg 35:437-439, 2001

10. Metzler G, Schaumburg-Lever G, Hornstein O, Rassner G: Malignant chondroid syringoma: immunohistopathology. Am J Dermatopathol 18:83-89, 1996

11. Requena C, Brotons S, Sanmartín O, Llombart B, Traves V, Guillén C, et al: Malignant chondroid syringoma of the face with bone invasion. Am J Dermatopathol 35:395-398, 2013

12. Rosborough D: Malignant mixed tumours of skin. Br J Surg 50:697-699, 1963

13. Schiano di Visconte M, Picciano P: Chondroid syringoma. A case report. Chir Ital 54:241-244, 2002

14. Shashikala P, Chandrashekhar HR, Sharma S, Suresh KK: Malignant chondroid syringoma. Indian J Dermatol Venereol Leprol 70:175-176, 2004

15. Sivamani R, Wadhera A, Craig E: Chondroid syringoma: case report and review of the literature. Dermatol Online $\mathbf{J}$ 12:8, 2006

16. Solomonov A, Rosenblatt E, Ben-Izhak O, Goralnik L, Yigla M: High-dose-rate endobronchial brachytherapy in endobronchial metastatic malignant chondroid syringoma. Respiration 68:406-410, 2001

17. Sun TB, Chien HF, Huang SF, Shih TT, Chen MT: Malignant chondroid syringoma. J Formos Med Assoc 95:575-578, 1996

18. Takahashi H, Ishiko A, Kobayashi M, Tanikawa A, Takasu $\mathrm{H}$, Tanaka M: Malignant chondroid syringoma with bone invasion: a case report and review of the literature. Am J Dermatopathol 26:403-406, 2004

19. Trown K, Heenan PJ: Malignant mixed tumor of the skin (malignant chondroid syringoma). Pathology 26:237-243, 1994

20. Tural D, Selçukbiricik F, Günver F, Karışmaz A, Serdengecti S: Facial localization of malignant chondroid syringoma: a rare case report. Case Rep Oncol Med 2013:907980, 2013

21. Watarai A, Amoh Y, Aki R, Takasu H, Katsuoka K: Malignant chondroid syringoma: report of a case with lymph node metastasis 12 years after local excision. Dermatol Online $\mathbf{J}$ 17:5, 2011

22. Watson JA, Walker MM, Smith NP, Hunt DM: Malignant chondroid syringoma - a rare cause of secondary bone tumour. Clin Exp Dermatol 16:306-307, 1991

\section{Author Contributions}

Conception and design: Menéndez. Acquisition of data: Erice. Analysis and interpretation of data: Bas. Drafting the article: Menéndez, Casas. Critically revising the article: Bas, Dillon. Reviewed submitted version of manuscript: Dillon.

\section{Correspondence}

Ricardo Horacio Menéndez, Department of Neurosciences, Hospital Aleman, Pueyrredon 1640, Buenos Aires 1118AAT, Argentina.email: rhmenendez@hotmail.com. 